\title{
Repeated Headache as Presentation of Pituitary Apoplexy in the Adolescent Population: Unusual Entity with Review of Literature
}

Sir,

Pituitary apoplexy is a well-known clinical syndrome characterized by sudden onset of headache, commonly associated with vomiting, signs of meningeal irritability, opthalmoplegia, and visual deterioration. ${ }^{[1-13]}$ Pituitary tumor is the intracranial neoplasm having bleeding frequency of 5.4 times higher than any other primary intracranial neoplasm. ${ }^{[2]}$ Pituitary apoplexy is considered as a relatively rare clinical emergency which results from hemorrhage or infarction in the pituitary gland. Pituitary apoplexy in adolescent age is very rare occurrence. The incidence of apoplectic presentation of pituitary adenoma varies in literature between $15 \%$ and $27.7 \% \cdot{ }^{[10,11]}$ About twenty cases of pituitary apoplexy are reported in literature in the pediatric age below 15 years of age, mostly in the form of isolated case report. The management and outcome of pituitary apoplexy in the adolescent patient is still poorly understood. Pituitary apoplexy occurrences in childhood are rare event, through reported..$^{[1,3-16]}$

A 12-year-old boy had suffered two episodes of sudden onset headache at interval of 1 month. He reported the hospital at current admission on the same day of occurrence of the second episode of severe headache with fresh decline in visual acuity involving both eyes first episode 1 month back with diminution of visual acuity; he was managed by local practitioner with subsidence of headache and mild visual improvement. There was no history of hyposexuality, poyuria, or other major medical illness. He had good scholastic performance at his school. On admission, he was consciousness and his neck was supple. His visual acuity was $6 / 9$ in the right eye and 6/36 in the left eye. He had bitemporal field defect. The pupils were assymetrical and brisk light reflex. The optic fundi were normal, muscle strength of extremities was normal, and there were no associate pathological reflexes. His secondary sexual characteristics were normal. The hematological and biochemical profile were normal. Endocrinologist evaluation revealed that hormone levels were within normal limits.

The cone view sella revealed normal size sella. The cranial computed tomography (CT) scan done at the time of current admission revealed blood in the 
sella. Magnetic resonance imaging (MRI) axial and sagittal view showed sellar mass with suprasellar component having heterogeneous hyperintense signal on T1-weighted image, suggestive of recent bleed in the pituitary adenoma [Figures 1 and 2] and showing heterogeneous enhancement on contrast administration in axial section and sagittal view images [Figures 3 and 4]. He was given a trial of medical therapy, but his headache and visual acuity did not show improvement, and finally, he was taken up for microscopic sublabial transsphenoidal surgical approach and pituitary adenoma decompression was carried out. During surgery, there was soft suckable grayish mass with evidence of altered blood. Histopathology revealed chromophobe pituitary adenoma with evidence of necrosis and hemorrhage. Immunohistochemistry revealed negative reactivity for growth hormone as well as prolactin. He showed improvement in the vision in the immediate

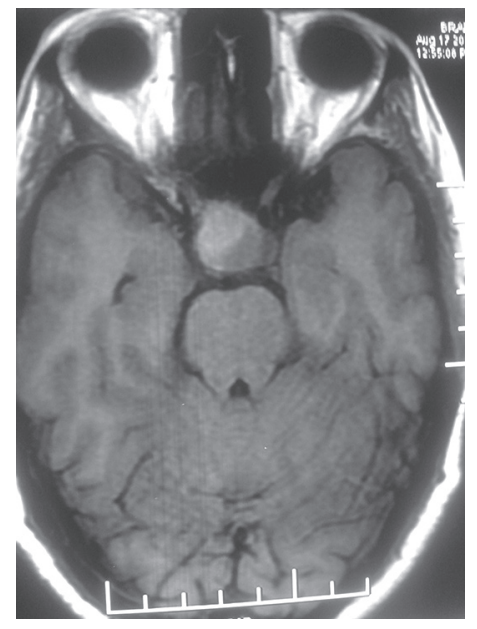

Figure 1: Magnetic resonance imaging brain axial section T1-weighted image showing large sella-suprasellar mass

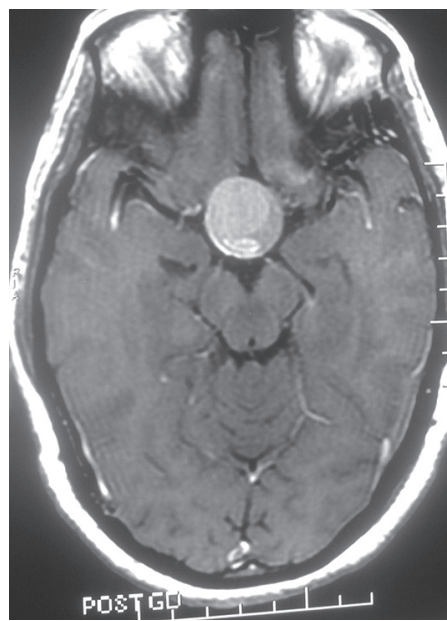

Figure 3: Contrast-enhanced axial section magnetic resonance imaging brain showing large sella-suprasellar mass having heterogeneous enhancement postoperative period. His vision improved in both eyes. He was doing well till he last follow-up 3 years following surgery.

Pituitary apoplexy represents cascade of complex clinical events, occurring following fulminate expansion of a pituitary tumor by hemorrhage, infarction or combination, which involves tumor and neighboring pituitary gland. ${ }^{[12,17,18]}$ There is a spectrum of presentation of pituitary apoplexy, which may vary from subclinical infarction observed during the surgery or on preoperative imaging study to full blown apoplexy mimics subarachnoid hemorrhage. ${ }^{[11]}$ Exact pathophysiological mechanism of pituitary apoplexy is still remains ill-understood. Ischemic necrosis of adenomatous tissue, compression of superior hypophyseal arteries against diaphragma sella, and intrinsic vasculopathy of pituitary tumor has been suggested as possible mechanism of pituitary apoplexy. To the best of authors' knowledge,

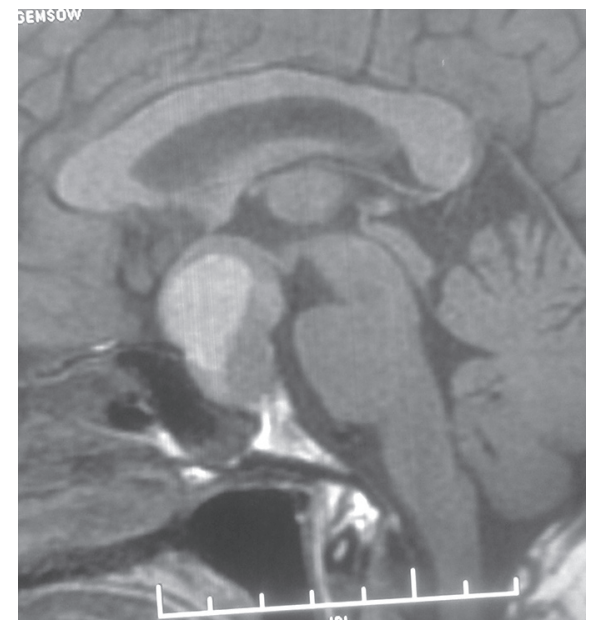

Figure 2: Magnetic resonance imaging sagittal section T1-weighted image of brain showing large sellar-suprasellar mass

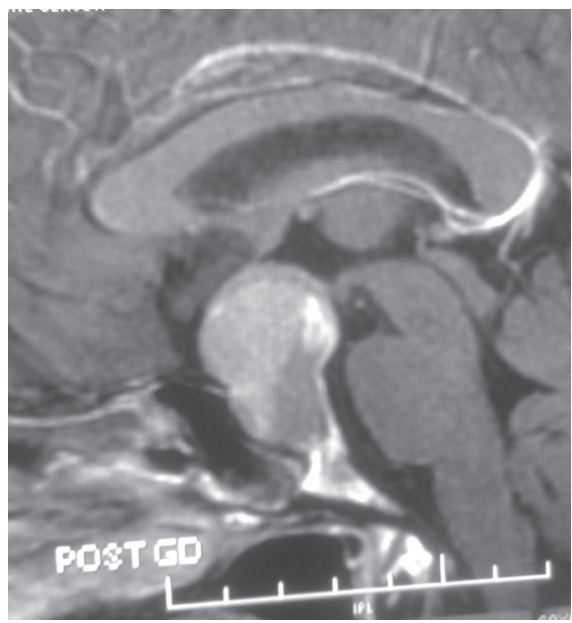

Figure 4: Magnetic resonance imaging brain, contrast-enhanced sagittal section image showing large heterogeneous enhancement mass in sellarsuprasellar region 
only twenty cases of pituitary apoplexy, in pediatric cases below 15 years of age, have been reported including our current case. ${ }^{[1,3-9]}$ All reported cases presented with the first episode of a headache occurring 4 days to 18 months before admission. Uniquely, our case suffered two episode of intense headache unlike other reported cases and represents first case in the western literature of its kind. However, majority of cases noticed complete relief of a headache on admission. However, current patient suffered twice episodic severe headache at the interval of month, last being on the day of admission. Seven patients underwent cranial CT scan, but definite diagnosis could only be made in four cases.

The CT scan can visualize bleed inside pituitary adenoma, which is best seen within first few days but with passage of time after apoplexy, subacute and chronic bleed state in that cases may pose difficulty in differentiating from other sellar lesions. However, MRI brain is usually a better modality of investigation that demonstrates better anatomical delineation and also predicts the probable age of bleed. ${ }^{[1,3,5,8,19]}$

Surgical decompression of apoplectic pituitary adenoma offers a good result, preferably with transsphenoidal approach. Accurate preoperative diagnosis with suitable modality of neuroimaging study with early surgery and selectively removal of adenoma and hematoma provides a suitable solution in developing children with possible low morbidity, who is suffering from pituitary adenoma. ${ }^{[14,16-19]}$

Jankowski et al. retrospectively analyzed a series of nine patients suffering with pituitary hemorrhage, who were managed surgically in 2015 at Rady's Children's Hospital - San Diego, with six female and headache was most common presentation observed in all cases and visual disturbance $(n=6)$ was second most common symptoms. Duration of clinical symptoms varied from few days to 1 year. Hormonal evaluation showed hyperprolactinemia in 7 patients, and six out of whom had associated galactorrhea. Magnetic resonance imaging study revealed sellar remodeling and hemorrhage in sella in all cases. All patients underwent transsphenoidal decompression except one. ${ }^{[16]}$

Jankowski et al. concluded pituitary hemorrhage resulting in clinically manifest or subclinical apoplexy in adolescents may represent a clinically pathologically and radiologically distinct entity with characteristically associated with relatively indolent symptomatology and more favorable outcome in respect to neurological and endocrine dysfunction, compared with adult. ${ }^{[16]}$

Chao and Lin reported a 14-year-old girl presenting with blurred vision, nausea, and headache with pituitary apoplexy and review the literature. Neuroimaging revealed the presence of suprasellar mass and was managed with microscopic endonasal transsphenoidal surgery, and intraoperatively, about $10 \mathrm{cc}$ of brownish fluid-like material was evacuated and noticed improvement in vision following surgery. Moreover, author further concluded although the incidence of pituitary apoplexy is rare in pediatric age, however, prompt detailed ophthalmic, biochemical, endocrine evaluation, and appropriate neuroimaging study are very important for diagnosis as well as planning of appropriate management without delay. ${ }^{[13]}$

Kasl et al. reported a 14-year-old female with apoplectic prolactin secreting pituitary macroadenoma presenting with stuttering cerebral infarction, who presented with complaint of paresthesia involving the right hand and word-finding difficulty. Magnetic resonance imaging study revealed the presence of apoplectic macroadenoma, and diffusion-weighted imaging demonstrates acute stroke involving the left anterior and middle cerebral artery territory, and MR angiography focal compression supraclinoidal segment of the left internal carotid artery. However, vasospasm can also present with stroke-like symptoms. ${ }^{[14]}$

Kamboj et al. reported a case of hemorrhagic pituitary apoplexy in an 18-year-old male with previously undiagnosed diabetes mellitus who presented with unexplained hyperglycemia and altered sensorium with presumptive diagnosis of nonketotic hyperglycemic coma. However, MRI brain revealed the presence of heterogeneous mass arising from sella and extending into the suprasellar cistern and managed with emergency transsphenoidal surgery. ${ }^{[19]}$ Mehrazin analyzed 21 cases of pituitary adenoma patients with the age of less than 18-year-old and managed with surgery, and had two mortality in their series, one of which was because of apoplexy. Authors concluded biological behavior of pediatric pituitary adenomas seems more aggressive than adults' adenomas. The chance of pituitary apoplexy in pediatric invasive pituitary adenoma is relatively high. ${ }^{[20]}$ Satyarthee and Mahapatra reported a child presented with a sudden onset of headache and diminution of visual acuity. Magnetic resonance imaging showed blood in the sella with massive subarachnoid and intraventricular hemorrhage, who underwent transsphenoidal decompression apoplectic pituitary adenoma, and noticed improvement of vision with resolution of a headache in the postoperative period. ${ }^{[21]}$

Every pediatrician, ophthalmologist, radiologist, and neurologist should be aware of occurrence of such rare but clinically important benign clinical entity, which 
is completely amenable to surgical management and may need appropriate hormonal replacement therapy with relatively excellent prognosis. Every adolescent patients presenting with a history of intense headache, visual disturbances or stroke, a possibility of pituitary apoplexy must be entertained and appropriate early radiological investigation must be carried out. A high degree of clinical suspicion of pituitary apoplexy along with suitable neuroimaging is required for prompt and early diagnosis. An early surgical decompression is also advisable to provide good visual, neurological, and endocrinal outcome. The tumor decompression can help in preservation of vision and can prevent consequent morbidity of pituitary apoplexy from getting permanent clinical sequlae.

\section{Financial support and sponsorship}

Nil.

\section{Conflicts of interest}

There are no conflicts of interest.

Guru Dutta Satyarthee, B. S. Sharma Department of Neurosurgery, Neurosciences Centre, AIIMS, New Delhi, India

Address for correspondence: Dr. Guru Dutta Satyarthee, Department of Neurosurgery, Neurosciences Centre, AIIMS, Room No. 714, New Delhi, India. E-mail: duttaguru2002@yahoo.com

\section{REFERENCES}

1. Ando T, Sakai N, Yamada H, Yano K, Nishimura Y, Shimokawa K. A case of prolactin secreting adenoma in childhood. Childs Nerv Syst 1989;14:455-62.

2. Wakai S, Yamakawa K, Manaka S, Takakura K. Spontaneous intracranial hemorrhage caused by brain tumor: Its incidence and clinical significance. Neurosurgery 1982;10:437-44.

3. Arisaka O, Hall R, Hughes IA. Spontaneous endocrine cure of gigantism due to pituitary apoplexy. Br Med J (Clin Res Ed) 1983;287:1007-8.

4. Kaplan B, Day AL, Quisling R, Ballinger W. Hemorrhage into pituitary adenomas. Surg Neurol 1983;20:280-7.

5. Kimura H, Fukushima T, Aikawa H, Takagi T, Tomonaga M. Pituitary apoplexy in a child. Nerv Syst Child 1989;14:57-62.

6. Sakalas R, David RB, Vines FS, Becker DP. Pituitary apoplexy in a child. Case report. J Neurosurg 1973;39:519-22.

7. Shirataki K, Takeda N, Tamaki N, Matsumoto S. Spontaneous reduction in the size of pituitary adenomas following pituitary apoplexy - Serial CT evaluation in two cases. Rinsho Hoshasen 1987;32:649-52.

8. Uozumi T, Mori S, Watanabe M, Takimoto N, Mogami H. Endocrinological evaluation of sellar and suprasellar tumor cases (the seventh report) - Endcrinological study on four cases of pituitary adenoma with intratumoral hemorrhage (author's transl). No Shinkei Geka 1976;4:557-65.
9. Sugita S, Hirohata M, Tokutomi T, Yamashita M, Shigemori M. A case of pituitary apoplexy in a child. Surg Neurol 1995;43:154-7.

10. Cardoso ER, Peterson EW. Pituitary apoplexy: A review. Neurosurgery 1984;14:363-73.

11. Anderson JR, Antoun N, Burnet N, Chatterjee K, Edwards O, Pickard JD, et al. Neurology of the pituitary gland. J Neurol Neurosurg Psychiatry 1999;66:703-21.

12. Rovit RL, Fein JM. Pituitary apoplexy: A review and reappraisal. J Neurosurg 1972;37:280-8.

13. Chao CC, Lin CJ. Pituitary apoplexy in a teenager - Case report. Pediatr Neurol 2014;50:648-51.

14. Kasl RA, Hughes J, Burrows AM, Meyer FB. Pediatric ischemic stroke from an apoplectic prolactinoma. Childs Nerv Syst 2015;31:1387-92.

15. Pinto G, Zerah M, Trivin C, Brauner R. Pituitary apoplexy in an adolescent with prolactin-secreting adenoma. Horm Res 1998;50:38-41.

16. Jankowski PP, Crawford JR, Khanna P, Malicki DM, Ciacci JD, Levy ML. Pituitary tumor apoplexy in adolescents. World Neurosurg 2015;83:644-51.

17. Bao Y, Yoshida D, Morimoto D, Teramoto A. Expression of laminin beta2: A novel marker of hypoxia in pituitary adenomas. Endocr Pathol 2006;17:251-61.

18. Shah SA, Pereira JK, Becker CJ, Aronin PA. Pituitary apoplexy in adolescence: Case report. Pediatr Radiol 1995;25 Suppl 1:S26-7.

19. Kamboj MK, Zhou P, Molofsky WJ, Franklin B, Shah B, David R, et al. Hemorrhagic pituitary apoplexy in an 18 year-old male presenting as non-ketotic hyperglycemic coma (NKHC). J Pediatr Endocrinol Metab 2005;18:611-5.

20. Mehrazin M. Pituitary tumors in children: Clinical analysis of 21 cases. Childs Nerv Syst 2007;23:391-8.

21. Satyarthee GD, Mahapatra AK. Pituitary apoplexy in a child presenting with massive subarachnoid and intraventricular hemorrhage. J Clin Neurosci 2005;12:94-6.

This is an open access article distributed under the terms of the Creative Commons Attribution-NonCommercial-ShareAlike 3.0 License, which allows others to remix, tweak, and build upon the work non-commercially, as long as the author is credited and the new creations are licensed under the identical terms.

\begin{tabular}{|l|l|}
\hline \multicolumn{2}{|c|}{ Access this article online } \\
\hline Quick Response Code: & Website: \\
& www.ruralneuropractice.com \\
\cline { 2 - 2 } & \\
\hline
\end{tabular}

How to cite this article: Satyarthee GD, Sharma BS. Repeated headache as presentation of pituitary apoplexy in the adolescent population: Unusual entity with review of literature. J Neurosci Rural Pract 2017;8:S143-6.

(C) 2017 Journal of Neurosciences in Rural Practice | Published by Wolters Kluwer - Medknow 